\title{
AN ANALYSIS OF INFECTION RISK CAUSED BY THE COMPOUND DISASTER OF A LARGE EARTHQUAKE WITH FLOODING IN AN URBAN RIVER CATCHMENT
}

\author{
NAOKO NAKAGAWA ${ }^{1}$, AKIRA KAWAMURA ${ }^{2} \&$ HIDEO AMAGUCHI ${ }^{2}$ \\ ${ }^{1}$ Department of Physics, Rikkyo University, Japan. \\ ${ }^{2}$ Department of Civil and Environmental Engineering, Tokyo Metropolitan University, Japan.
}

\begin{abstract}
In addition to torrential rainfall and typhoon damage which occur frequently in Tokyo, there is the possibility of the occurrence of a massive metropolitan direct-hit earthquake. In other words, the risk of a compound disaster generated by heavy rain and flooding after a big earthquake is high in the Tokyo metropolitan area. In this case, the situation that raw sewage flows due to the destruction of the sewer pipe network and the waste from temporary lavatories installed after a massive earthquake, are expected to combine with floodwater and it is considered that the infection risk will increase remarkably. Therefore, in this study, the risk assessment technique of pathogens was applied to a compound disaster of a large earthquake with a flood using the Tokyo Storm Runoff model and an evaluation method of the infection risk was proposed. The infection risks of the norovirus and cholera vibrio were calculated quantitatively using the Kanda River basin as the study area. The spatial distribution of the infection risk was created and the visualization of the infection risk was investigated. The results for the metropolitan area, where functionality is normally high, for a single disaster, it is shown when it suffers a compound disaster, such as being hit by a great earthquake and a flood, it was found that the infection risk changes in a range of 1.2 to 10 times higher than usual in the case of a large earthquake with a flood and subsequent inland inundation. Thus, not only care of physical externally caused injuries, but also that of infectious diseases is vital in such compound disasters.
\end{abstract}

Keywords: compound disaster, earthquake, flood, infection risk, urban, spatial distribution.

\section{INTRODUCTION}

The Great East Japan Earthquake (magnitude 9.0) occurred on Friday, March 11, 2011, and the sewage systems were intensely damaged. As a result, the condition of the hygienic situation became inferior, and the risk of exposure to pathogens was considered to be increased in the disaster area because the flushing toilets which need a sewage treatment system were unusable. On the other hand, in addition to torrential rainfall and typhoon damage which occur frequently, the possibility of the concurrent occurrence of a massive earthquake, such as a metropolitan direct-hit earthquake, has been increasing in the Tokyo metropolitan area in recent years. In other words, the risk of a compound disaster generated by heavy rain and a flood after a big earthquake is a distinct possibility in the Tokyo metropolitan area. In this case, the situation that the raw sewage flows from pipes due to the destruction of the sewer pipe network and the waste from the temporary lavatories installed after a massive earthquake are expected to combine with flood waters and it is considered that the infection risk will increase remarkably.

There has been research in the past to clarify the relationship between flooding and drainage system infections [1]. However, developing Asian nations were selected for the study area in that research, and no evaluation of the infection risk during compound disasters in urban areas with complex rainfall and sewage networks as in Tokyo prefecture have been evaluated. The authors propose to use the TSR (Tokyo Storm Runoff) [2] as an analytical 
model for flood discharge and inundation process in urban basins. It is a flood discharge model utilizing GIS data which is capable of faithfully representing all features which make up the urban basin such as the buildings, parking areas, and the pervious green spaces that exist in the blocks of land in addition to the sewer pipe systems, roads and rivers. In the TSR model, it is possible to simultaneously analyze all the flows including direct discharge, ground surface/overflow, channel flow and sewer pipe flows.

Regarding the TSR model, flooding analysis was conducted in an upper stream basin, the Egoda River basin of the Kanda River, which is a typical urban river in the Tokyo prefecture, with verification of flood damage evaluation [2]. Furthermore, flood damage with rain water/ sewage pipe damage during an earthquake, the verification was conducted assuming torrential rainfall occurred in the Tokai area in the Kanda River upper stream basin [3].

Therefore, in this study, the risk assessment technique of pathogens was applied to a compound disaster of a large earthquake with a flood and an evaluation method of the infection risk was proposed to establish a risk assessment technique of pathogens for the compound disaster of a great earthquake and flood. The infection risks of the norovirus and cholera vibrio were calculated quantitatively using the Kanda River basin as the study area. The spatial distribution of the infection risk was created and the visualization of the infection risk was investigated.

\section{FEATURE OF THE STUDY AREA}

The origin of Kanda River, which is the target area of this research, is at Inogashira pond in Mitaka city. Merging with Zenpukuji River and Myoshoji River and inflowing into Sumida River, Kanda River is a typical river in Tokyo prefecture. In this study, the Kanda River upper stream basin (basin area $11.5 \mathrm{~km}^{2}$, stream length $9 \mathrm{~km}$ ) from Inogashira pond to the merger point with Zenpukuji River was selected as the study area. Figure 1 shows the schematic of the Kanda River upstream basin. The population in the basin is more than 1.6 million, and the coverage ratio of sewage installation with the combined sewer system has reached $100 \%$ [4].

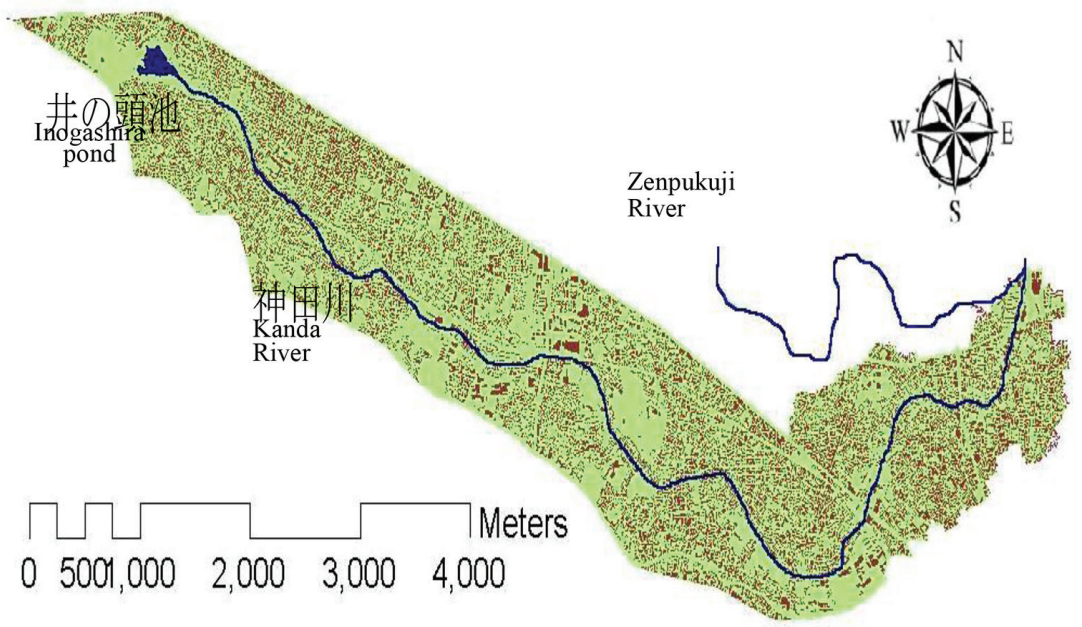

Figure 1: Schematic of the Kanda River upstream basin. 


\section{RUNOFF INUNDATION ANALYSIS IN THE CASE OF A COMPOUND DISASTER OF A LARGE EARTHQUAKE WITH A FLOOD USING TSR MODEL}

When a large-scale earthquake occurs, it is expected that combined sewer pipes will break as was the case in the Great East Japan Earthquake. Because there were no individual surveys conducted on the pipe breakage points in the Kanda River upstream basin during previous earthquakes, a liquefaction distribution in the Kanda River upstream basin was specified and assumed that the combined sewer pipes would break within the region in this study.

The Tokyo Government's Disaster Prevention Council evaluates the liquefaction risk level with a $250 \mathrm{~m}$ mesh, and the Kanda River upstream basin not only has several grid squares with high liquefaction risk levels, but also many lowland grid squares exist along the river which are designated as requiring more detailed survey due to important structures, although the liquefaction risk itself is low. Therefore, in order to understand the range where there is liquefaction risk, the land condition maps [5, 6] issued by the Geographical Survey Institute were used to specify suitable sections as sewer pipe breakage points in the surrounding embankment areas of targeted rivers which were topographically classified as lowlands. Figure 2 shows a basin map which displays embankments abstracted using land use factors in red, and others in green. In this study, a simulation was conducted assuming that the combined sewer pipes in the areas displayed in red do not exist.

Furthermore, the runoff analysis of cases with and without the earthquake damage (combined sewer pipes breakage) were performed and compared each other.

In this study, rainfall of a maximum of $50 \mathrm{~mm}$ of rainfall per $60 \mathrm{~min}$ was used, which is the design rainfall of the combined sewer pipes in Tokyo prefecture. This rainfall was for $3 \mathrm{hr}$ of continuous rainfall with a total rainfall volume of $96 \mathrm{~mm}$. Furthermore, the hypothetical rainfall targeted in this study was based upon the AMeDAS rainfall probability calculation program. A runoff inundation analysis with and without combined sewer pipes breakage was conducted using the TSR model which can satisfactorily reproduce actual flood areas with high reliability. First, the hydrograph of the river flow at the downstream edge of the Kanda River upstream basin is displayed in Figure 3.

Comparing the River flow with and without breakage gives a peak flow difference of 20 $\mathrm{m}^{3} / \mathrm{s}$ or greater. The difference in river flows between with and without the breakage exist at the upstream basin, indicating that smooth function of the storm water and sewage removal function has been lost due to the combined sewer pipes breakage. Second, the maximum inundation depth for each feature in the basin found via the runoff inundation analysis is displayed in Figure 4. The inundation has a wider range in the breakage case than that without

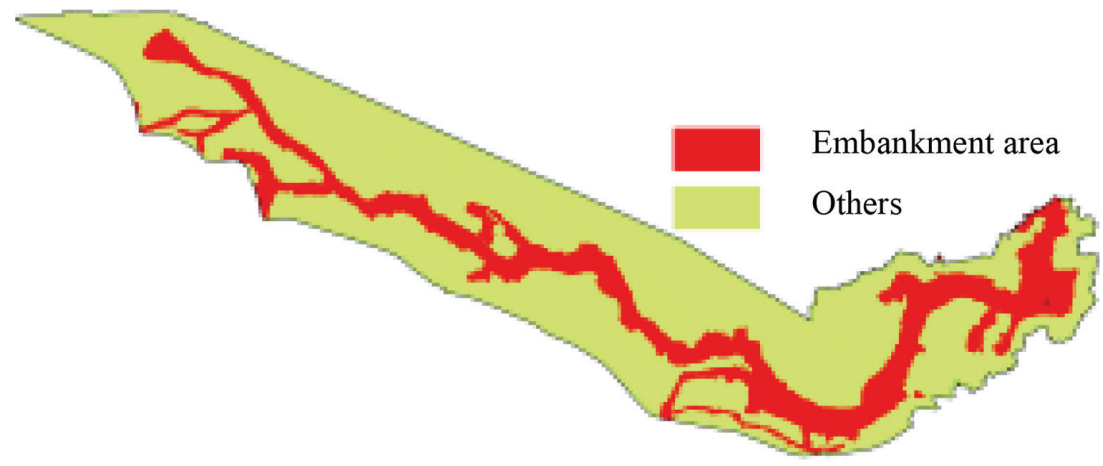

Figure 2: Basin map with the sewer pipe breakage points. 


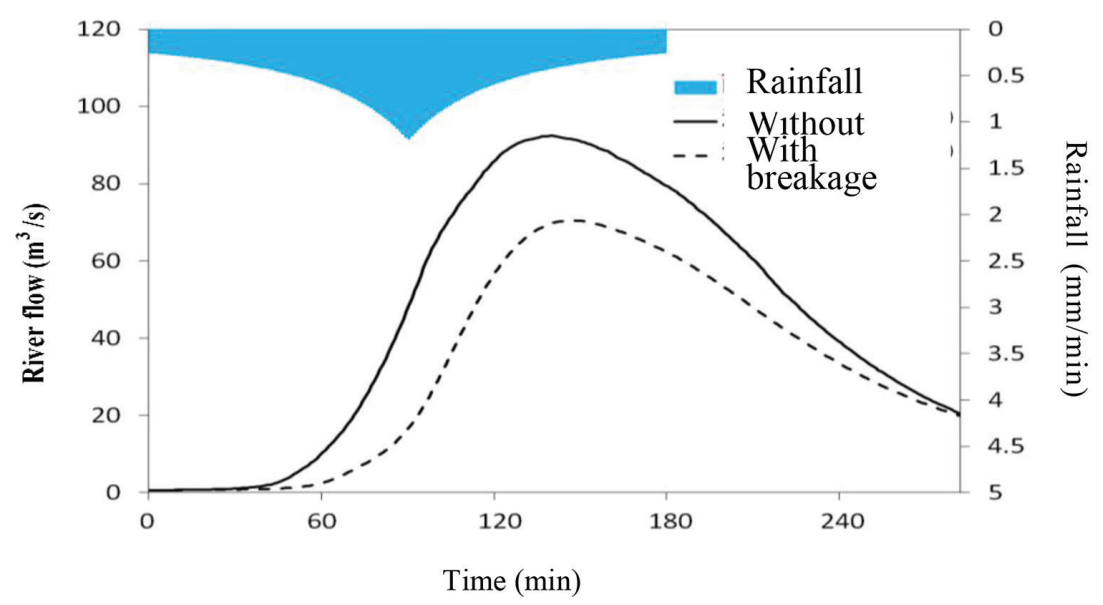

Figure 3: Hyetograph and hydrograph.

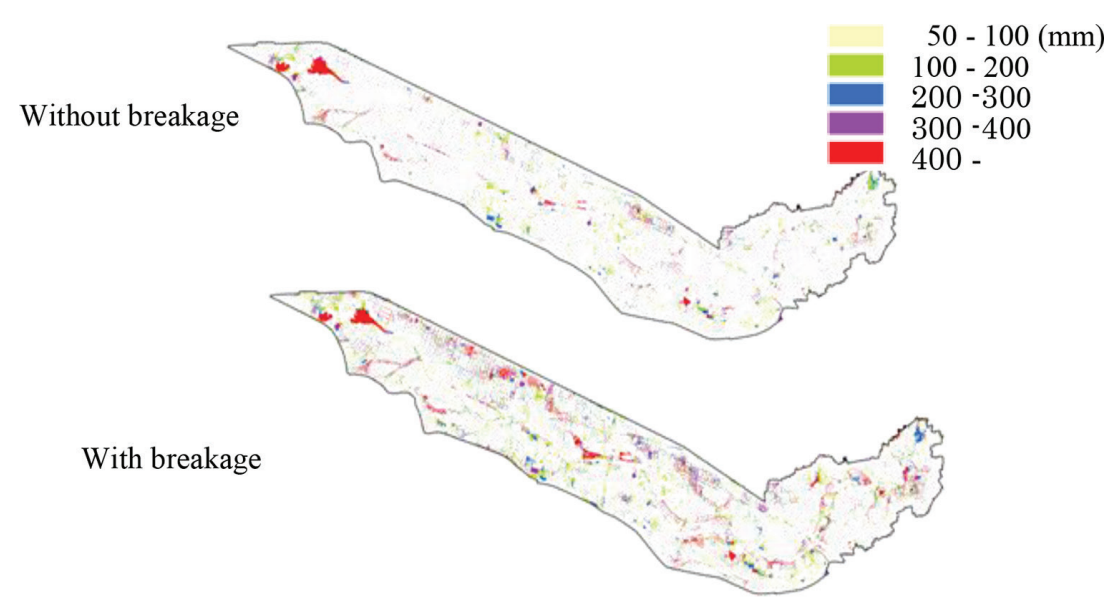

Figure 4: Maximum inundation depth.

breakage, and it can be seen that the inundation depth also tends to increase. The results obtained show that this causes the scope of the inland inundation received when combined sewer pipes are broken increases and that there is a tendency for the inundation depth in many areas to increase as well.

\section{MICROBIAL RISK ASSESSMENT CAUSED BY THE COMPOUND DISASTER OF AN EARTHQUAKE AND FLOOD}

In this study, we calculated the pathogenic infection risk based on the aforementioned maximum inundation depth. Risk evaluation is defined as a quantitative or qualitative evaluation of the health hazards posed to people and animals that are exposed to the risk factors (chemical substances and pathogenic microorganism). The risk evaluation methods were developed from the 1970s to the 1980s mainly by the National Academy of Sciences and were compiled 
in a report by the United States National Research Council in 1983 [7]. In this study, these risk evaluation methods were applied and evaluated the pathogenic infection risk according to the following procedures over the areas of inundation occurring both with and without breakage to combined sewer pipes.

\subsection{Hazard Identification}

Paying attention to enteric pathogens, such as norovirus which has many outbreak examples in Japan and vibrio cholera which has a strong infectious ability and of which outbreaks actually occurred after large earthquakes in Haichi. From the high concentration in the feces of the infected people, these were selected for the reference pathogens.

\subsection{Dose-response assessment}

Several models that show the relationship between the intake dose of the pathogen and the microbial risk have been proposed by Haas [8] and Rose [9]. The appropriate infective model was used. The dose-response model used for the risk evaluation of norovirus and cholera vibrio in this study is displayed in eqns (1) and (2), and the relation between dose and response based on these is displayed as a graph in Figure 5.

$$
\begin{aligned}
& \text { Beta model (cholera vibrio) } P(D)=1-[1+(D / \beta)]^{--} a \\
& \text { Exponential model (norovirus) } P(D)=1-\exp (-\gamma \mathrm{D})
\end{aligned}
$$

where, $\mathrm{P}(\mathrm{D})$ : infection risk, $\mathrm{D}$ : the amount of intake dose, $\alpha(=0.164), \beta(=0.149), \gamma(=0.0069)$ [10]: model parameter

\subsection{Exposure assessment}

Flood water can be considered as a mixture of storm water and sewage, and when accidentally ingested by a human, poses a pathogenic infection risk through the pathogenic microorganism found in the sewage. Using the aforementioned runoff inundation analysis, the maximum inundation depth when inundation via target rainfall occurs is shown in

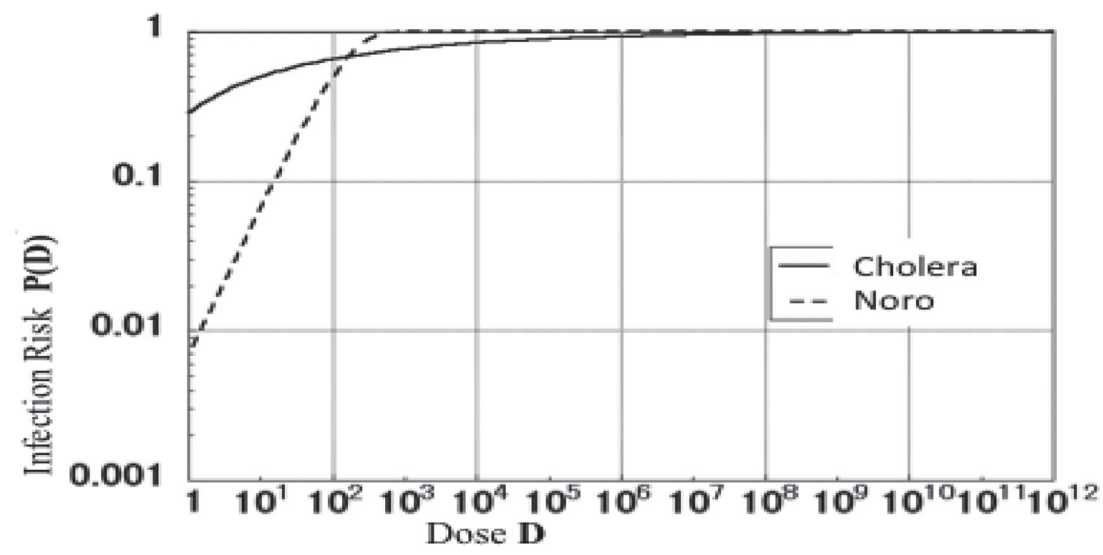

Figure 5: Relation between dose and response for cholera vibrio and norovirus. 
Figure 4. There seem to be many uncertain factors regarding the relationship between water depth and water ingested volume, however, as it would seem that higher water depth would also increase the water intake volume. In this study, the relationship between inundation depth and flood water intake volume adhered to the saturation curve indicated in eqn. (3) was assumed as shown below.

$$
y=A \tanh (x / b)
$$

where $y$ is the intake volume $(\mathrm{mL}), \mathrm{A}$ is a parameter, $\mathrm{x}$ is water depth $(\mathrm{mm})$ and $\mathrm{b}$ is a parameter. Parameter A denotes the saturation value of the intake volume, but because we were unable to confirm data which could be the intake water volume when nearly drowning, 200 $\mathrm{mL}$ was assumed to be the volume ingested each time. Furthermore, although the parameter $b$ is connected to the slope of the saturation curve, therefore the following three types of curve were tried and a sensitivity analysis conducted.

Saturated curve 1 through $(0,0),(500,150)(b=500 / \operatorname{Arc} \tanh (150 / 200)=514)$

Saturated curve 2 through $(0,0),(1000,150)(b=1000 / \operatorname{Arc} \tanh (150 / 200)=1028)$

Saturated curve 3 through $(0,0),(2000,150)(b=2000 / \operatorname{Arc} \tanh (150 / 200)=2056)$

The saturation curves are shown in Figure 6. Regarding the pathogenic microorganism density in the flood water, it is considered that the pathogenic microorganism density [11] found in the literature would be diluted by the storm water. The average sewage volume of the Kanda River upstream basin is $0.007 \mathrm{~mm} / \mathrm{min}$ [4], therefore the sewage volume of $3 \mathrm{hr}$ would seem to be about $1.26 \mathrm{~mm}$. Furthermore, because $3 \mathrm{hr}$ total rainfall of the storm rainfall is 96 $\mathrm{mm}$, assuming the sewage and rain water completely mixed together the level of dilution by the rain water would be about 76 times. Because not all the sewage in the sewer pipes would come up into the flood water on the ground, the ratio of rain water should be higher than that of the sewage; therefore, in this study, a dilution by rain water of 100 times was assumed. The concentration in sewage, dilution rate, and concentration of pathogenic microorganism in flood water are displayed in Table 1. Moreover, as there are large fluctuations in the amount of norovirus in sewage depending on the season, in this study the value for January, which is when the concentration in sewage rises was used. Under these assumptions, the pathogenic

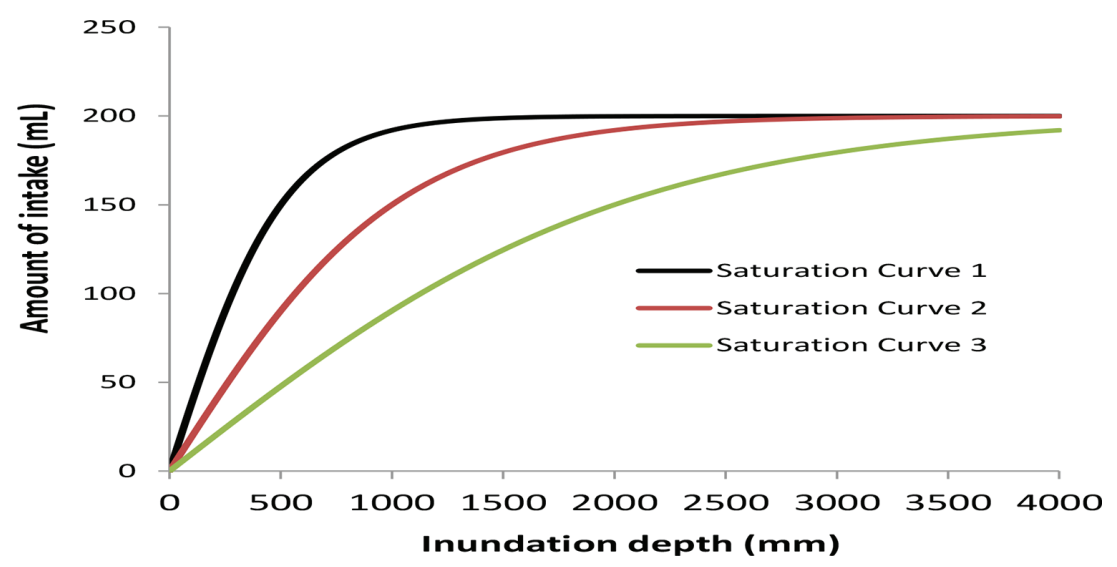

Figure 6: Relation between the inundation depth and the intake volume. 
Table 1: Concentration and dilution rate of the reference pathogens.

\begin{tabular}{llll}
\hline & $\begin{array}{l}\text { Concentration in } \\
\text { sewage }(/ \mathrm{L})\end{array}$ & $\begin{array}{l}\text { Dilution rate } \\
\text { (times) }\end{array}$ & $\begin{array}{l}\text { Concentration of pathogenic } \\
\text { microorganism in flood water(/L) }\end{array}$ \\
\hline Norovirus & $10^{6.2}$ & 100 & $10^{4.2}$ \\
Cholera vibrio & $10^{2}$ & 100 & 1 \\
\hline
\end{tabular}

infection risk for the maximum inundation depth considering the various features within the basin was calculated.

\section{RESULTS AND DISCUSSION}

Using the relationship curves 1, 2 and 3 between the inundation depth and intake volume displayed in Figure 6, the pathogenic infection risks for the maximum inundation depth displayed in Figure 4 were calculated based on the infection risk calculation method mentioned in 'Microbial risk assessment caused by the compound disaster of a great earthquake and flood', and the spatial distribution was displayed on the basin. The infection risks of norovirus and cholera vibrio in cases of combined sewer pipes breakage and no breakage for curves 1 and 3 are shown in Figure 7. Regarding the norovirus infection, in a) and b) 0.5 1,

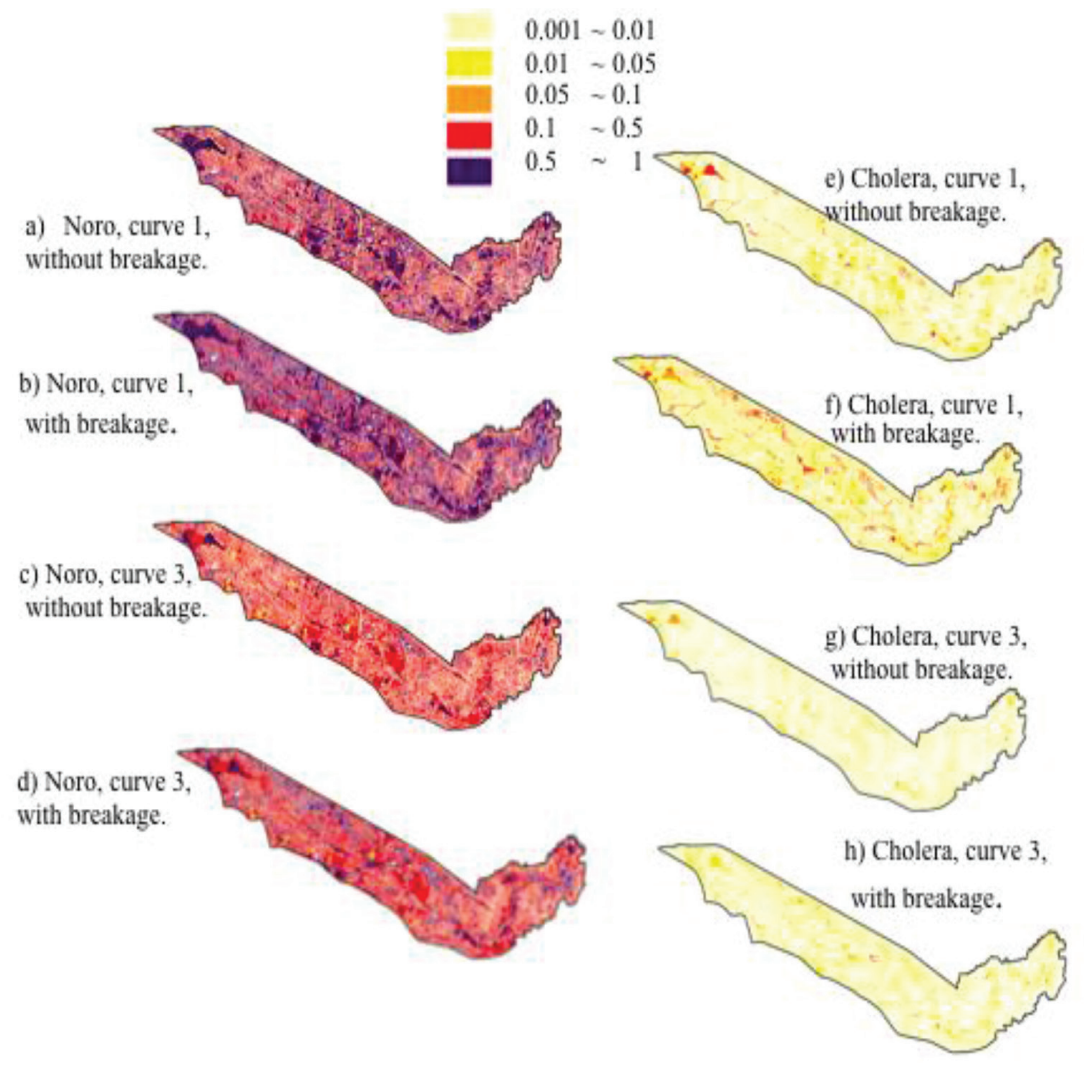

Figure 7: Infection risk. 
and in c) and d) 0.1 0.5 account for the majority of cases. There are many areas where the infection risk exceeds 0.1 , which is an extremely high value. The infection risk is definitely increased in a wide area of the basin in cases with breakage compared to the no breakage case. However, in the case of norovirus, even when the combined sewer pipes are not broken, there are many areas where infection risk exceeds 0.1 , indicating that sufficient caution against infection is required. Regarding cholera vibrio, the infection risk of the basin overall is roughly transitioning from 0.001 to 0.1 , but in e) and f) there are some areas where the infection risk exceeds 0.1 . The infection risk in cases with breakage is increased compared to that with no breakage for the cholera vibrio as well as the norovirus. The infection risks for cholera vibrio are lower than norovirus, but they greatly exceed the acceptable microorganism infection risk by the United States Environmental Protection Agency of $10^{-4}$ per year and cannot easily be called safe levels. Comparing the infection risk of the norovirus and cholera vibrio in Figure 7, it is shown that the infection risk of the norovirus is overwhelmingly higher, but this difference is largely due to the concentration of the pathogenic microorganism in the sewage. As shown in Table 1, the concentration of norovirus in sewage is $10^{6.2} / \mathrm{L}$, while the concentration of cholera vibrio in sewage is $10^{2} / \mathrm{L}$, a large difference.

This is the reason of high infection risk value of norovirus. However, the major symptoms of norovirus are acute gastroenteritis such as vomiting and diarrhoea and usually recover in a few days. While cholera is a dangerous infection that can easily lead to rapid dehydration and lowering of body temperature due to massive diarrhoea, and even death due to disturbance of blood flow, especially in an environment where clean water to ensure sanitized conditions cannot be obtained such as after earthquakes, where cases of cholera outbreaks at communal refuge shelter are prevalent. Therefore, the risks of secondary infection which could lead to pandemic, the risk level of cholera therefore cannot be considered low.

\section{CONCLUSIONS}

In this study, we conducted an analysis of runoff inundation at normal times and when combined sewer pipes are broken targeting the Kanda River upstream basin using the TSR (Tokyo Storm Runoff) model, which is capable of faithfully representing all features which make up the urban basin utilizing GIS data while also conducting a quantitative evaluation of the infection risks of norovirus and cholera vibrio. The infection risks were visualized by displaying the infection risk due to whether the combined sewer pipes were broken or not and the fluctuation as a spatial distribution on the basin. The results showed that with norovirus, even in cases where there is no breakage of combined sewer pipes there are still many areas with infection risk values exceeding 0.1 , and the infection risk tends to increase even further if the combined sewer pipes are broken due to an earthquake. While cholera vibrio does not have as high an infection risk as norovirus, when the combined sewer pipes are broken there are areas where the infection risk exceeds 0.1 .

During earthquake/high rainfall compound disasters, there are more areas with inundation than at normal times, and the maximum inundation depth also tends to increase. Accordingly, this increases opportunities for contact with pathogenic microorganism, and we can conclude that the pathogenic infection risk also increases by about $1.2-10$ times when sewer pipes are broken compared to when they are not broken. This suggests that even in urban areas with normally good sanitation conditions and high functionality, when earthquake/high rainfall compound disasters occur there is a high risk of pathogenic infection. 


\section{REFERENCES}

[1] Kazama, S., Aizawa, T., Watanabe, T., Ranjan, P., Gunawardhana, L. \& Amano, A., A quantitative risk assessment of waterborne infectious disease in the inundation area of a tropical monsoon region. Sustainability Science, 7(1), pp. 45-54, 2012. https://doi.org/10.1007/s11625-011-0141-5

[2] Amaguchi, H., Kawamura, A., Olsson, J. \& Takasaki, T., Development and testing of a distributed urban storm runoff event model with a vector-based catchment delineation. Journal of Hydrology, 420-421, pp. 205-215, 2012. https://doi.org/10.1016/j.jhydrol.2011.12.003

[3] Amaguchi, H., Kawamura, A. \& Nakagawa, N., Inundation assessment under the damage situation by earthquake of stormwater drainage system. Journal of Japan Society and Civil Engineering B1, 69(4), pp. 1609-1614, 2013. https://doi.org/10.2208/jscejhe.69.i_1609

[4] Takasaki, T., Kawamura, A., Amaguchi, H. \& Araki, K., New storage function model considering urban runoff process. Journal of Japan Society and Civil Engineering B, 65(3), pp. 217-230, 2009. https://doi.org/10.2208/jscejb.65.217

[5] Geographical Survey Institute, Figure of land condition, West Tokyo, 2011.

[6] Geographical Survey Institute, Figure of land condition, Kichijoji, 2011.

[7] Kaneko, M., Pathogenic microorganism measures for the water service, Maruzen publishing, Tokyo, pp. 219-225, 2006.

[8] Haas, C., Estimation of risk due to low doses of micro-organisms: a comparison of alternative methodologies. American Journal of Epidemiology, 118, pp. 573-582, 1983. https://doi.org/10.1093/oxfordjournals.aje.a113662

[9] Rose, J.B. \& Gerba, C.P., Use of risk assessment for development of microbial standards. Water Science Techonology, 24(2), pp. 29-34, 1991.

[10] Masago, Y., Katayama, H., Watanabe, T., Haramoto, E., Hashimoto, A., Omura, T., Hirata T. \& Ohgaki, S., Quantitative risk assessment of noroviruses in drinking water based on qualitative data in Japan. Environmental Science \& Technology, 40, pp. 7428-7433, 2006. https://doi.org/10.1021/es060348f

[11] Kaneko, M., Quality of the Water Hygienics, Gihodo publishing, Tokyo, p. 438, 1996. 